\title{
Characterisation of Self-Weight Consolidated Paste Backfill
}

T. Belem, O. Eı Aatar, B. Bussière, M. Benzaazoua, M. Fall, E. Yilmaz Université du Québec en AbitibiTemiscamingue, Canada

\section{INTRODUCTION}

Recent studies showed that for a given mix recipe and curing time the unconfined compressive strength (UCS) of in situ paste backfill (PB) core samples can be 2 to 4 times higher than samples of the same PB mix poured into plastic moulds (Belem et al., 2002; le Roux et al., 2002; Cayouette, 2003; Revell, 2004). Also, the same observations were made for PB samples prepared and cured in laboratory conditions compared to in situ underground PB samples (Belem et al., 2000 and 2001). These differences in compressive strength could be attributed at least in part to the PB hardening (e.g. Benzaazoua et al., 2004) conditions in the stope such as: stope size and geometry, stope walls convergence against the fill mass and its resulting shrinkage (Belem et al., 2004). Other factors of influence are the amount of bleeding water and the gravity-driven consolidation settlement of the PB mass which may depend on its physico-geochemical properties and also on the physical properties of the surrounding rock mass. It was reported that this self-weight consolidation settlement can reach more than $1 \mathrm{~m}$ and is usually considered to positively affect the PB strength development (e.g. Belem et al., 2002; le Roux, 2002; Cayouette, 2003). A relatively large number of experimental studies are reported in the literature on the self-weight consolidation of granular slurries, debris, dredge materials or waste rock and mine tailings (e.g. Been and Sills, 1981; Wickland and Wilson, 2005). The originality of the present study, however, is that it considers high density slurry (solids mass concentration ranging from $70 \%$ to $85 \%$ $\mathrm{w} / \mathrm{w})$. To the knowledge of the authors, only very few investigations on the consolidation behaviour of PB have been completed to date (e.g. Belem et al., 2002; le Roux et al., 2002).

The purpose of this paper is to characterize the physical and mechanical properties of PB prepared at Louvicourt mine paste backfill plant, poured and cured into $3 \mathrm{~m}$ high PVC/Makrolon ${ }^{\circledR}$ polycarbonate sheet settling columns following three scenarios: fully-drained (FD), half-drained (HD) and undrained (UD) conditions. The main objective is to better understand the effect of self-weight consolidation settlement of $\mathrm{PB}$ on its physical and mechanical properties.

\section{MATERIAL AND METHODS}

\subsection{Self-weight consolidation test set-up}

In order to simulate the PB placement in underground mine stope and its state, three PVC/Makrolon ${ }^{\circledR}$ polycarbonate sheet columns were manufactured. These columns allow simulating the stope backfilling 
sequences as well as various PB drainage configuration scenarios. Figure 1 presents a schematic diagram of the experimental set-up.

(a) Top view of one column

(b) Undrained

(c) Half-drained

(d) Fully-drained

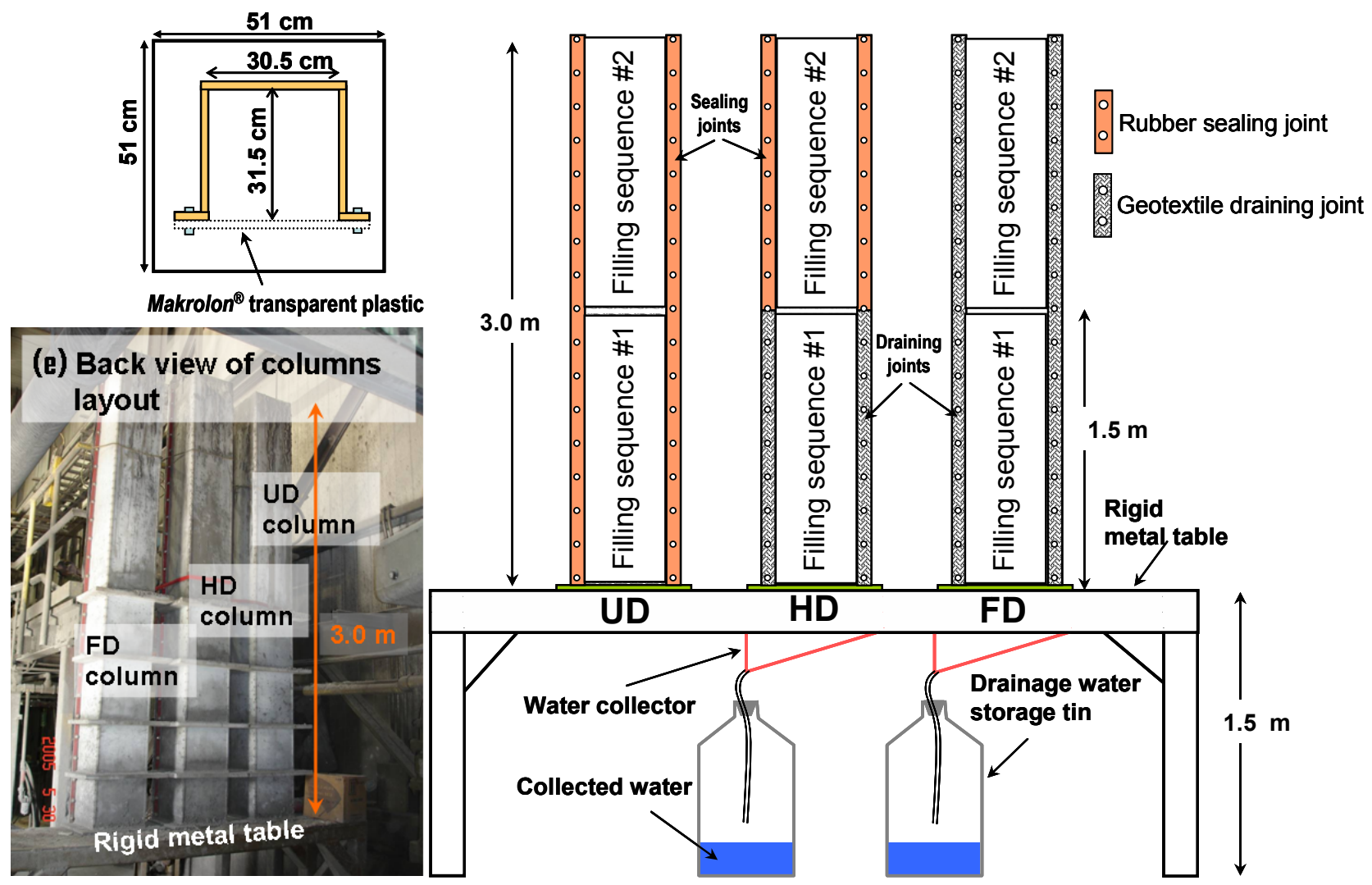

\section{Figure 1 Schematic diagram of the experimental set-up showing a photograph of the} set-up at Louvicourt mine paste backfill plant

The columns have $31.5 \mathrm{~cm}$ x $30.5 \mathrm{~cm}$ section and $300 \mathrm{~cm}$ height. They are made out of PVC on three sides (forming a U-shape) which are closed by a Makrolon ${ }^{\circledR} G P$ transparent polycarbonate sheet allowing the visual follow-up of the column filling. The first column simulates the undrained condition (UD column) of a backfilled stope and is equipped with rubber sealing joints (see Figure 1b). The second column simulates a partial drainage condition (HD column) of a backfilled stope and is equipped with rubber sealing joint at its upper-half and with a permeable geotextile joint at its lower-half (see Figure 1c). Finally, the third column simulates the fully-drained condition (FD column) over the entire height of a backfilled stope and is equipped over its entire height with a permeable geotextile joint (Figure 1d). The HD and FD columns are also equipped with tins for the drainage water collection and storage. The base of the three columns is impervious; this corresponds to the assumption that the drainage will not occur at the base of a backfilled stope but rather on its side-walls through the surrounding fractured rock mass or already existing backfill mass. 


\section{$2.2 \quad$ Experimental program}

\subsubsection{Paste fill preparation at backfill plant}

The tests were carried out at the Louvicourt mine paste backfill plant which is located in the northwest part of Quebec, about $600 \mathrm{~km}$ north from Montreal and about $25 \mathrm{~km}$ east from Val d'Or. The paste backfill used at Louvicourt mine is made up of partially deslimed tailings $(5 \%<20 \mu \mathrm{m})$, recycled mine process water and binding agent composed of ordinary Portland cement (OPC or Type 1) and ground granulated blast furnace slag (GBFS) in a ratio of 20:80. Table 1 summarizes the PB mix parameter values and its calculated physical parameters.

\section{Table $1 \quad$ Paste fill mix parameters and its calculated physical parameters}

\begin{tabular}{|l|l|}
\hline Paste fill mix parameters & Value \\
\hline Binder content by mass, $B_{\mathrm{M} \%}$ & $4.5 \mathrm{wt} \%$ \\
\hline Binder content by volume, $B_{\mathrm{v} \%}$ & $5.5 \% \mathrm{v} / \mathrm{v}$ \\
\hline Sulphur content & $16-19 \mathrm{wt} \%$ \\
\hline Specific gravity of tailings $\left(\mathrm{SG}_{\mathrm{t}}\right.$ or $\left.\mathrm{G}_{\mathrm{s}-\mathrm{t}}\right)$ & 3.53 \\
\hline Specific surface area of tailings $S_{\mathrm{m}}$ & $1.721 \mathrm{~m}^{2} / \mathrm{g}$ \\
\hline $\begin{array}{l}\text { Solid mass concentration }\left(C_{\mathrm{M} \%}=\right. \\
\left.100 * M_{\text {solid }} / M_{\text {bulk }}\right)\end{array}$ & $75.8 \% \mathrm{w} / \mathrm{w}$ \\
\hline $\begin{array}{l}\text { Solid volume concentration }\left(C_{\mathrm{V} \%}=\right. \\
\left.100 * V_{\text {solid }} / V_{\text {bulk }}\right)\end{array}$ & $47.3 \% \mathrm{v} / \mathrm{v}$ \\
\hline Gravimetric water content $\mathrm{w} \%$ & $31.9 \%$ \\
\hline Water-to-cementitious ratio $(W / C)$ & 7.4 \\
\hline
\end{tabular}

\begin{tabular}{|l|l|}
\hline Paste fill physical parameters & Value \\
\hline Degree of saturation $S_{\mathrm{r}}$ & $100 \%$ \\
\hline Initial void ratio $e$ & 1.12 \\
\hline Initial porosity $n$ & 0.53 \\
\hline Volumetric water content $\theta$ & 0.53 \\
\hline Bulk density $\rho_{\text {bulk }}$ & $2180 \mathrm{~kg} / \mathrm{m}^{3}$ \\
\hline Bulk unit weight $\gamma_{\text {bulk }}$ & $21.4 \mathrm{kN} / \mathrm{m}^{3}$ \\
\hline Dry density $\rho_{\mathrm{d}}$ & $1652 \mathrm{~kg} / \mathrm{m}^{3}$ \\
\hline Dry unit weight $\gamma_{\mathrm{d}}$ & $16.2 \mathrm{kN} / \mathrm{m}^{3}$ \\
\hline Specific gravity $\left(\mathrm{SG}_{\mathrm{f}}\right.$ or $\left.\mathrm{G}_{\mathrm{s}-\mathrm{f}}\right)$ & 3.50 \\
\hline
\end{tabular}

\subsubsection{Columns filling, curing and sample coring}

At the end of the mixing process the Louvicourt mine PB has an initial standard cone slump height of $17 \mathrm{~cm}$ (6.7"). But usually, on-site observations showed that the initial slump height can increase by a value of about $2.54 \mathrm{~cm}(1$ ") during its transportation in pipelines from the backfill plant to underground stopes due to the pipe wall shearing (e.g. Cayouette, 2003). In order to take this important factor into account, the fresh PB was re-mixed in a concrete mixer for about 20 minutes to obtain a standard cone slump height of about 19.8 $\mathrm{cm}$ (7.8”). Then the 3 columns were fully filled in two filling sequences of $150 \mathrm{~cm}$ over 24 hours. Also, a part of the re-mixed PB was poured into 6 plastic moulds $(10.16 \mathrm{~cm}$ diameter and $20.32 \mathrm{~cm}$ height $)$ as laboratory scale undrained control samples. These moulds were sealed and placed in a humidity chamber controlled at approximately $70 \%$ relative humidity $(\mathrm{RH})$ and $23^{\circ} \mathrm{C}$ for a curing periods of 10,28 and 59 days. Twenty five hours after the columns are filled, the drainage water from FD and HD columns and the bleeding water from the UD column are collected and weighed. The PB self-weight consolidation settlement was manually measured for each column at a time interval of about 1 hour. The total duration of the measurements was 5 days. The filled columns are then maintained under the backfill plant ambient conditions for a total curing time of 45 days. At the end of this time period, the columns were dismantled and each PB column was cut into ten blocks corresponding to ten different elevations. From each PB block, two 
core samples were taken (twenty core samples for each column). The total of sixty core samples were then wrapped in paraffin film before being placed in the humidity chamber (at approximately $70 \% \mathrm{RH}$ and $23^{\circ} \mathrm{C}$ ) for final curing periods of 87 days (FD samples), 89 days (HD samples) and 91 days (UD samples). The PB samples (mould and core samples) were then subjected to unconfined compression tests and physical properties characterization.

\subsubsection{Unconfined compression tests}

The unconfined compression tests were performed on the core and the mould samples in duplicate. The compression tests were carried out using a MTS 10/GL universal press with a load capacity of $50 \mathrm{kN}$ and a minimum deformation rate of $0.0001 \mathrm{~mm} / \mathrm{min}$. All the samples were tested at a constant deformation rate of $1 \mathrm{~mm} / \mathrm{min}$ until reaching $80 \%$ of the peak stress. The accuracy of the load measurement is $\pm 1 \%$.

\subsubsection{Physical properties}

The following physical parameters were calculated for each PB sample: gravimetric water content $w \%$, volumetric water content $\theta$, solid mass concentration $C_{\mathrm{M} \%}$, specific gravity $\mathrm{G}_{\mathrm{s}}$, degree of saturation $S_{\mathrm{r}} \%$, void ratio $e$ (porosity $n)$ and specific surface area by mass $S_{\mathrm{m}}\left(\mathrm{m}^{2} / \mathrm{g}\right)$.

\section{RESULTS}

\subsection{Self-weight consolidation results}

\subsubsection{Collected drainage water and PB settlement}

The results of the pastefill drainage water collection and its self-weight settlement measurement are tabulated in Table 2. It was observed that from the total volume of PB water of 160.41 only 241 were collected from the fully-drained column (FD) and about 141 from the half-drained column (HD). These values correspond to a drainage percentage (regarding the total volume of water in the PB) of $15 \%$ and $8.4 \%$ respectively.

Table 2 Results of the paste fill drainage and settlement measurement

\begin{tabular}{|l|c|c|c|}
\hline \multicolumn{1}{|c|}{ Column type } & $\begin{array}{c}\text { Collected drainage } \\
\text { water (l) }\end{array}$ & $\begin{array}{c}\text { Percentage of drained } \\
\text { water (\%) }\end{array}$ & $\begin{array}{c}\text { Final settlement } \\
\boldsymbol{H}_{\mathbf{f}}(\mathbf{c m})\end{array}$ \\
\hline Fully-drained FD & 24 & 15 & 16.4 \\
\hline Half-drained HF & 14 & 8.4 & 8.5 \\
\hline Undrained UD & - & - & 7.5 \\
\hline
\end{tabular}


(a)

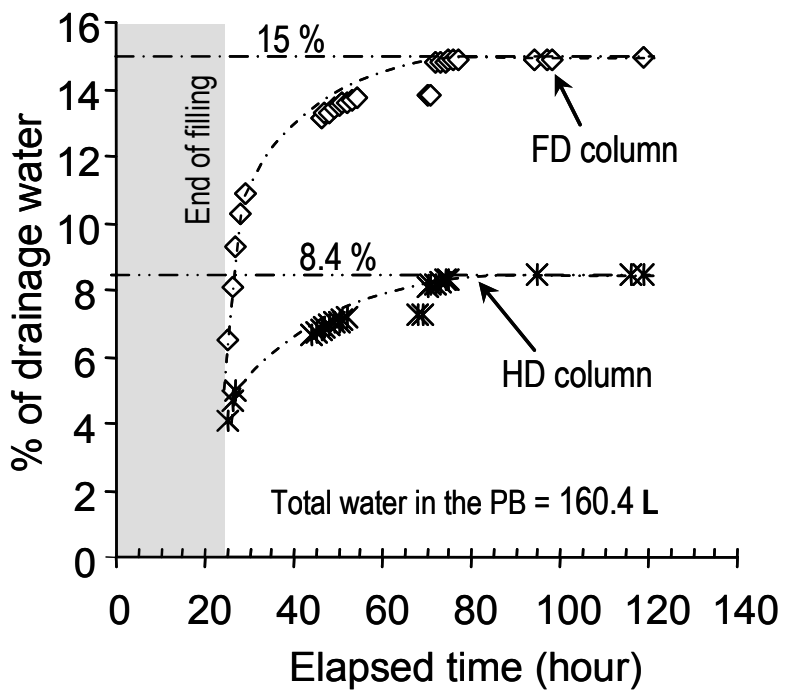

Elapsed time (hour)

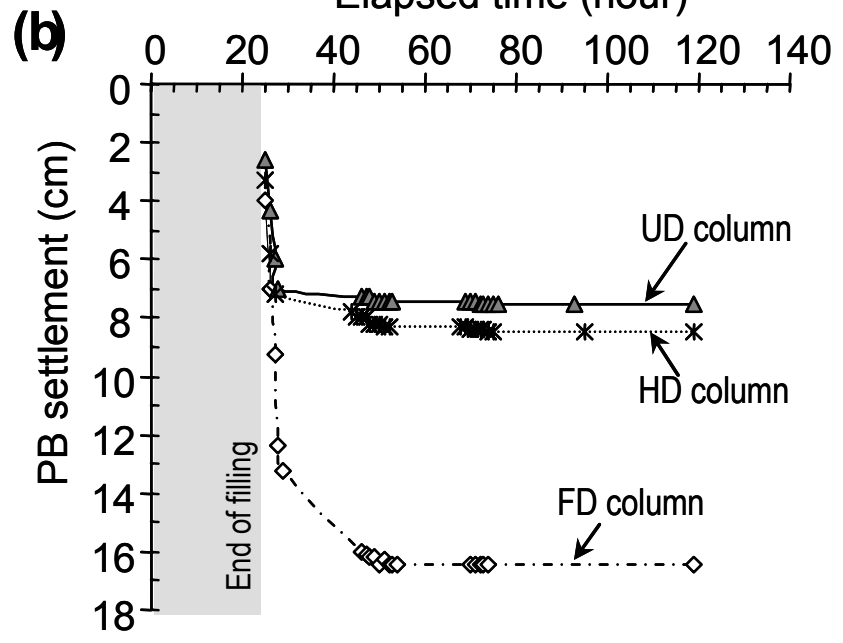

\section{Figure 2 Percentage of drainage water and PB settlement}

Figure 2 presents the evolution of the percentage of cumulative drainage water (Figure 2a) and the measured self-weight consolidation settlement $\Delta H$ of PB (Figure $2 \mathrm{~b}$ ) since the start of filling the columns. As expected, the drainage capacity of FD column is twice that of the HD column. Also, the observed settlement of the fully-drained column is twice that of the half-drained and undrained columns. The observed final settlements of PB $\left(\Delta H_{\mathrm{f}}\right)$ obtained from this figure are tabulated in Table 2. The self-weight consolidation settlement and drainage of all columns occurred mainly within the first 50 hours (see Figure 2). That means that little or no drainage/settlement occurs beyond 72 hours after a column filling. The observed Louvicourt mine stope paste backfill settlement varies between $100 \mathrm{~cm}$ and $150 \mathrm{~cm}$ for a mean stope height of $30 \mathrm{~m}$.

\subsubsection{Paste fill void ratio and volumetric strain}

The final void ratio $e_{\mathrm{f}}$ was calculated for each measured settlement increment $\Delta H$ using the formula:

$$
e_{f}=e_{0}-\left[\Delta H\left(1+e_{0}\right) / H_{0}\right]
$$

where $e_{0}=$ paste backfill initial voids ratio $(=1.12) ; H_{0}=$ paste backfill initial height $(=300 \mathrm{~cm})$. The volumetric strain $\left(\Delta V / V_{0}\right)$ is the ratio of the observed settlement and the PB initial height $\left(\Delta H / H_{0}\right)$. Table 3 contains the minimum final void ratio, the final settlement and the corresponding volumetric strain values of the column backfills. The change in initial void ratio $\left(\mathrm{e}_{0}=1.12\right)$ of FD and HD paste fill is due to the dissipation of the PB excess pore water pressure within 50 hours after the columns filling. In the case of the undrained column (UD) the excess pore pressure dissipation is attributed to the bleeding water at the top of the column. 
Table 3 Results of the paste fill drainage and settlement measurement

\begin{tabular}{|l|c|c|c|}
\hline \multicolumn{1}{|c|}{ Column type } & $\begin{array}{c}\text { Minimum void ratio } \\
\mathbf{e}_{\text {min }}\end{array}$ & $\begin{array}{c}\text { Final settlement } \\
\Delta \boldsymbol{H}_{\mathbf{f}}(\mathbf{c m})\end{array}$ & $\begin{array}{c}\text { Volumetric strain } \\
\boldsymbol{\Delta} \boldsymbol{H}_{\mathrm{f}} / \boldsymbol{H}_{\mathbf{0}}(\mathbf{\%})\end{array}$ \\
\hline Fully-drained FD & 1.00 & 16.4 & 5.5 \\
\hline Half-drained HF & 1.06 & 8.5 & 2.8 \\
\hline Undrained UD & 1.07 & 7.5 & 2.5 \\
\hline
\end{tabular}

(a)

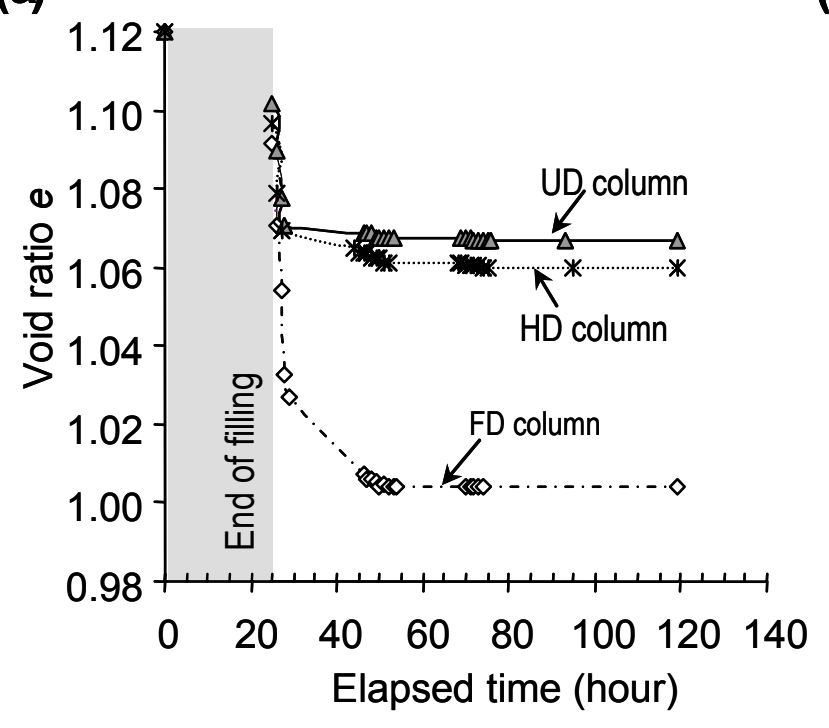

(b)

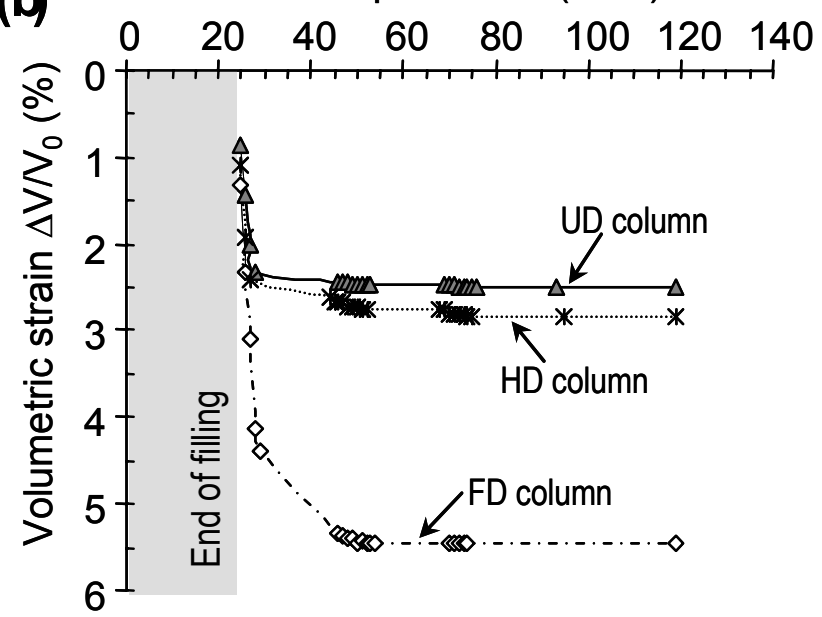

\section{Figure 3 Backfill void ratio and volumetric strain}

Figure 3 shows the variation in paste backfill final void ratio $e$ (Figure 3a) and the corresponding volumetric strain $\Delta H / H_{0} \%$ (Figure $3 \mathrm{~b}$ ) as a function of elapsed time after the end of filling. These results show that the observed strain of the FD backfill is twice the one of the HD and UD columns backfill. The behaviour of the UD backfill can be compared to that of the HD backfill. This apparent similarity can be explained by the columns configuration and their filling sequencing. The observed Louvicourt mine in situ paste backfill stope volumetric strain varies between $3.3 \%$ and $5.0 \%$ considering a mean stope height of $30 \mathrm{~m}$. That means that the in situ backfilled stopes behave in a similar way to the half-drained (HD) or the fully-drained (FD) conditions.

\subsection{Mechanical properties}

The mechanical properties evaluated from the compression tests are the unconfined compressive strength UCS and the modulus of elasticity $E$ of the paste backfill. Table 4 contains the value of these mechanical parameters for the mould backfill and the column PB core samples. 
Table 4 Mechanical properties of the column and mould paste fill samples

\begin{tabular}{|c|c|c|c|c|c|c|}
\hline \multirow{2}{*}{$\begin{array}{c}\text { Column } \\
\text { type }\end{array}$} & \multirow{2}{*}{$\begin{array}{l}\text { Curing time } \\
\text { (days) }\end{array}$} & \multirow{2}{*}{$\begin{array}{l}\text { UCS } \\
\text { (MPa) }\end{array}$} & \multirow{2}{*}{$\begin{array}{c}\mathbf{E} \\
(\mathbf{G P a})\end{array}$} & \multicolumn{2}{|c|}{ UCS for the filling sequence } & \multirow{2}{*}{$\begin{array}{l}\text { Predicted UCS } \\
\text { of undrained } \\
\text { moulds (MPa) }\end{array}$} \\
\hline & & & & $(0-150 \mathrm{~cm})$ & $(150-300 \mathrm{~cm})$ & \\
\hline FD & 87 & & $0.54-1.24$ & & & 2.14 (87-day) \\
\hline HD & 89 & $1.2-2.7$ & $0.75-1.20$ & increase & ase & 2.16 (89-day) \\
\hline UD & 91 & $1.4-2.4$ & $0.50-0.84$ & constant & increase & 2.18 (91-day) \\
\hline
\end{tabular}

In Table 4 the UCS of undrained mould backfill samples were predicted with an empirical relationship found from the UCS values of undrained mould PB samples cured at 10, 28 and 59 days:

$$
U C S_{U D_{-} \text {mould }}(\mathrm{kPa})=938.91 \times \operatorname{Ln}(t)-2054.2
$$

with $R=0.99$; where $t$ is the curing time in day.

Figure 4 presents the variation in the UCS (Figure 4a) and the modulus of elasticity $E$ (Figure $4 \mathrm{~b}$ ) of the mould PB samples and the column PB core samples as a function of their location $z$ in each column. The vertical straight line shown in Figure 4a corresponds to the predicted 91-day curing time UCS value of the undrained moulds PB.
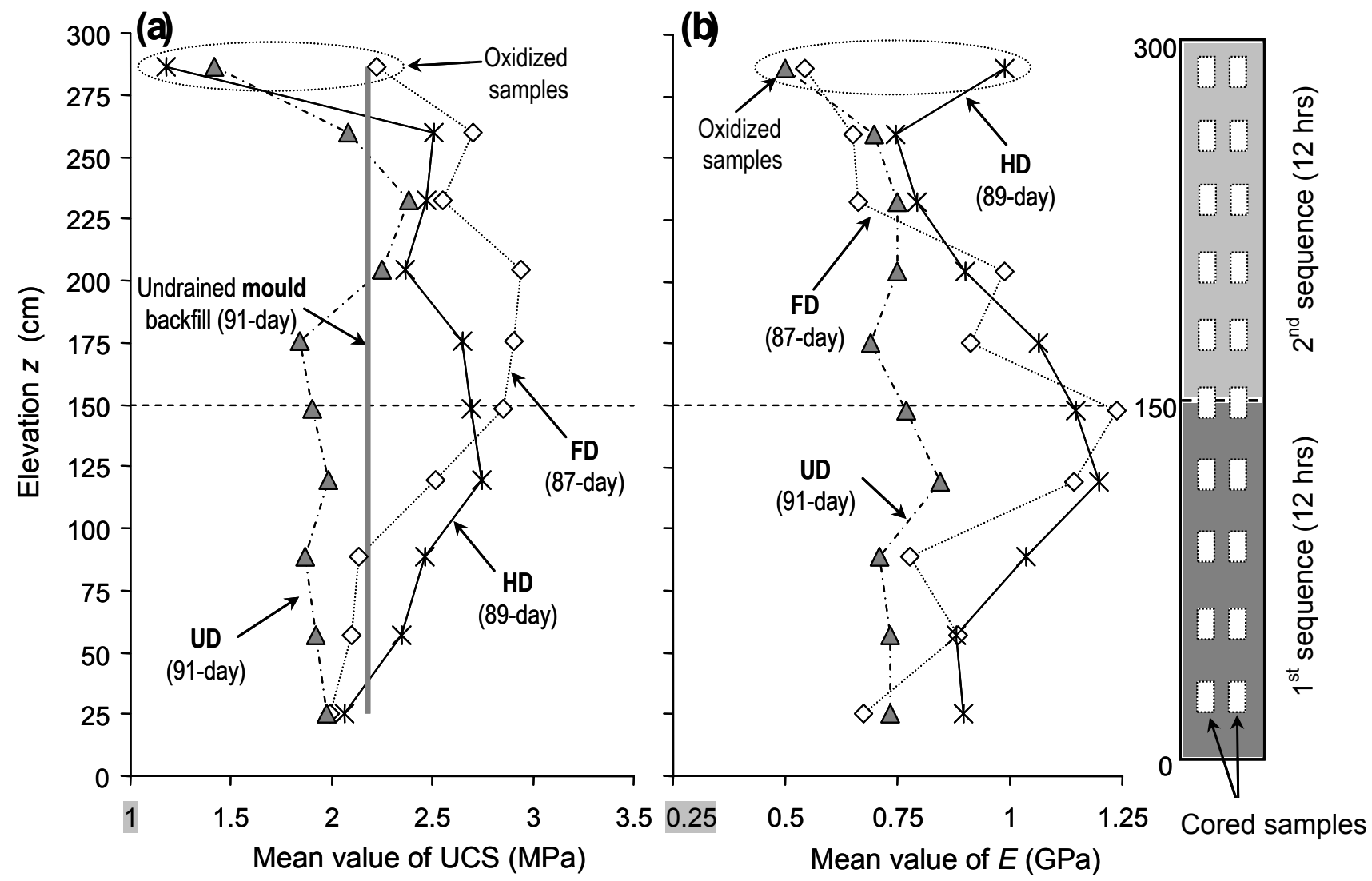

Figure 4

Variation of UCS and modulus of elasticity $E$, as a function of sample location 
Figure 4a shows that the UCS value of undrained mould PB is almost always higher than the UCS value of undrained column PB and is lower than the UCS value of the FD and HD paste fill. This result suggests that backfilled stopes are probably partially or entirely drained. But it should be noted however that the moulds do not take into account the sequencing of PB filling in the columns and were not cured under the same conditions than the columns. For example, the top of the columns was remained opened during curing process under Louvicourt mine backfill plant ambient air while the moulds were sealed and stored in a lab humidity chamber controlled at $70 \% \mathrm{RH}$ and $23^{\circ} \mathrm{C}$ temperature. Since there would be a linear relation between $E$ and UCS which is given by the following empirical relationship found from our data:

$$
E(M P a)=309.87 \times U C S(\mathrm{MPa})+97.172
$$

with $R=0.998$, almost the same reasoning would be applied to the variation of UCS and $E$.

It can be observed from Figure 4 that the variation of UCS and $E$ seems to be dictated not only by the curing time and the column configuration, but also by the sequencing of filling. As a matter of fact, the UCS value of the HD paste fill is higher than the one of the FD paste fill in the first layer $(0-150 \mathrm{~cm})$, and is lower than the one of FD backfill in the second layer $(150-300 \mathrm{~cm})$. Just after the first layer filling sequence $(0-150 \mathrm{~cm})$ the paste fill drains a part of its water in the case of the FD and HD columns, but separates from a part of its water in the case of the UD column. After the second layer filling sequence (150-300 cm), the HD paste fill can drain its water only through the PB sub-layer of $150 \mathrm{~cm}$ thick, while the FD paste fill can drain its water through this sub-layer as well as through the permeable geotextile joint. Concerning the UD column, the initial bleeding water at the top of PB sub-layer is imprisoned by the second PB layer and once the column is filled there is again a water separation on the top surface of $\mathrm{PB}$, a part will evaporate, and what remains will integrate the PB.

\subsection{Physical properties}

The physical parameters are evaluated after the compression tests. Figure 5 shows the variation in the physical parameters SG (specific gravity), $\mathrm{S}_{\mathrm{r}}$ (degree of saturation), $e$ (void ratio) and $S_{\mathrm{m}}$ (specific surface area) as a function of the sample location in the column.

Table 5 contains the range of variation of the physical parameters of the three columns paste backfill. The range of variation of the water content $w \%$ and the solid mass concentration $C_{\mathrm{M} \%}$ indicates a loss of a part of the PB initial water due to the: (i) water separation and its evaporation, (ii) drainage, (iii) self-weight consolidation of $\mathrm{PB}$ and, (iv) binder hydration. These combined effects will contribute to the PB hardening. 


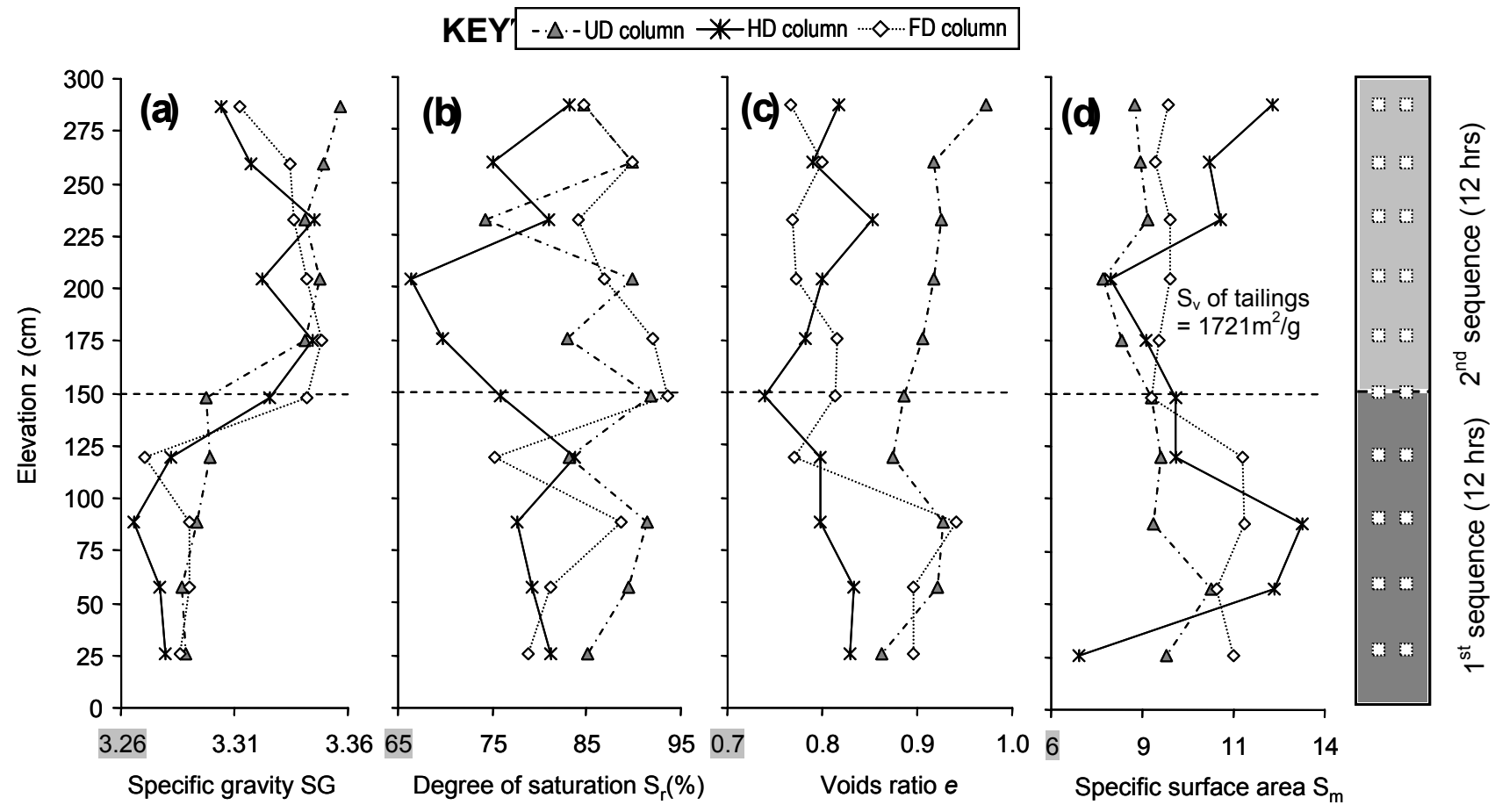

Figure $5 \quad$ Variation of some physical parameters as a function of the sample location

Table $5 \quad$ Range of variation of columns paste fill physical parameters

\begin{tabular}{|l|c|c|}
\hline Physical parameters & Initial value & Range of variation of the final value \\
\hline Gravimetric water content, $w \%$ & 31.9 & $15-25$ \\
\hline Solid mass concentration, $C_{\mathrm{M}}(\% \mathrm{w} / \mathrm{w})$ & 75.8 & $80-88$ \\
\hline Degree of saturation, $\mathrm{S}_{\mathrm{r}}(\%)$ & 100 & $70-90$ \\
\hline Volumetric water content, $\theta$ & 0.53 & $0.30-0.41$ \\
\hline Void ratio, $e$ & 1.12 & $0.70-0.90$ \\
\hline Porosity, $n$ & 0.53 & $0.40-0.48$ \\
\hline Specific gravity, $\mathrm{SG}$ or $\mathrm{G}_{\mathrm{s}-\mathrm{f}}$ & 3.50 & $3.25-3.35$ \\
\hline Specific surface area, $S_{\mathrm{m}}\left(\mathrm{m}^{2} / \mathrm{g}\right)$ & 1.72 (tailings) & $8-13$ \\
\hline
\end{tabular}

Specific gravity SG: Figure 5a shows that all the three columns paste backfill exhibits the same shape of SG profile. Even if the range of variation of SG does not seem very significant compared to what would be observed for in situ paste backfill, nevertheless one can say that this parameter highlights well the effect of the filling sequences. It can be observed that the SG is almost constant in each layer for the three columns with mean values of 3.29 for the first layer and of 3.34 for the second layer.

Degree of saturation $\mathbf{S}_{\mathbf{r}}$ : Figure $5 b$ shows that the half-drained (HD) paste backfill is the least saturated from the three columns at least for the second layer. It can also be observed that the degree of saturation of the FD and UD backfill exhibits a similar variation. Since the degree of saturation is the ratio of the volume of water and the volume of void $\left(\mathrm{S}_{\mathrm{r}}=V_{\mathrm{w}} / V_{\mathrm{v}}\right)$, this similarity mean that there is more volume of water and voids in the UD paste backfill than in the FD backfill ( $V_{\mathrm{w}_{-} \mathrm{UD}}>V_{\mathrm{w}_{-} \mathrm{FD}}$ and $\left.V_{\mathrm{v}_{-} \mathrm{UD}}>V_{\mathrm{v}_{-} \mathrm{FD}}\right)$.

Void ratio e: it can be seen from Figure $5 \mathrm{c}$ that the long-term void ratio (or porosity $n=e / 1+e$ ) of the undrained column backfill is almost constant over the entire PB height (no obvious densification of the PB) 
and is higher than the one of the FD and HD backfill $\left(e_{\mathrm{UD}}>e_{\mathrm{FD}} \approx e_{\mathrm{HD}}\right)$. These results corroborate the variation of the UCS value obtained from the three columns backfill core samples and shown in Figure 4a (the UCS value is higher for the lowest void ratios $e$ or porosity $n$ ).

Specific surface area $\mathbf{S}_{\mathbf{m}}$ : the specific surface area value includes both the fineness of the initial tailings and that of the binder hydration products. Figure $5 \mathrm{~d}$ shows the variation in the $\mathrm{S}_{\mathrm{m}}$ as a function of the PB sample location. The range of variation of $S_{m}$ shown in Table 5 seems to indicate a big increase of the PB material fineness due to the contribution of the binder hydration products. These observations are supported by previous $S_{m}$ data measurement on undrained mould PB samples cured at 91 days (Benzaazoua et al., 2000). For this study, four binder types have been used, each at $3 \mathrm{wt} \%, 4.5 \mathrm{wt} \%$ and $7 \mathrm{wt} \%$ (see Table 6): OPC-FA at a ratio of 50:50 (ordinary Portland cement and fly ash at a ratio of 50:50), OPC-SRPC at a ratio of 50:50 (OPC and sulphate-resisting Portland cement at a ratio of 50:50), OPC-Slag at a ratio of 20:80 (OPC and slag at a ratio of 20:80) and Slag at a ratio of 100\%. Table 6 shows that the maximum observed $\mathrm{S}_{\mathrm{m}}$ value for HD backfill cured at 89 days $\left(13 \mathrm{~m}^{2} / \mathrm{g}\right)$ was almost obtained for undrained mould backfill samples cured at 91 days $\left(12.5 \mathrm{~m}^{2} / \mathrm{g}\right)$. Table 6 also shows that the big increase in $\mathrm{S}_{\mathrm{m}}$ value might be more associated with the slag-based binding agent then with OPC only or blended OPC/SRPC binder.

\section{Table 6}

Specific surface area values of various undrained Louvicourt PB mix (data taken from Benzaazoua et al., 2000)

\begin{tabular}{|c|c|c|c|c|}
\hline Binder content & \multicolumn{4}{|c|}{$\mathbf{S}_{\mathbf{m}}\left(\mathbf{m}^{2} / \mathbf{g}\right)$ obtained from undrained mould samples after 91-day curing time } \\
\cline { 2 - 5 } $\boldsymbol{B}_{\mathbf{M}}(\mathbf{w t} \%)$ & OPC-FA (50:50) & OPC-SRPC (50:50) & OPC-Slag (20:80) & Slag only \\
\hline 0 & 1.7 & 1.7 & 1.7 & 1.7 \\
\hline 3 & 9.8 & 7.8 & 10.9 & 12.8 \\
\hline 4.5 & 10.1 & 12.0 & 12.5 & 14.9 \\
\hline 7 & 11.6 & 15.2 & 14.5 & 18.8 \\
\hline
\end{tabular}

\section{PRELIMINARY DISCUSSION}

Most of the previous parameters are interdependent (for example: $e \times \mathrm{S}_{\mathrm{r}}=w \times \mathrm{G}_{\mathrm{s}} ; n=e / 1+e ; C_{\mathrm{M} \%}=10^{4} /[100+w \%$; $\left.S_{\mathrm{r}}=\theta / n\right)$ except for the UCS and the specific surface area $S_{\mathrm{m}}$. Due to the difficulties to find a good correlation between the different parameters, only four relationships are selected to show their overall trends. Figure 6 presents the overall trends of $S_{\mathrm{r}}=f\left(C_{\mathrm{M} \%}\right), n=f\left(C_{\mathrm{M} \%}\right), S_{\mathrm{m}}=f(\mathrm{SG})$ and $\mathrm{UCS}=f(\mathrm{e})$.

It can be observed from Figure 6 that there are sometimes strong correlations between the various physical parameters for each layer of paste fill, but not for the entire paste fill column. This separation is due to the existence of a discontinuity separating the two sequences of paste fill (first and second layers). That is the reason why only overall trends can be highlighted instead of correlation. 

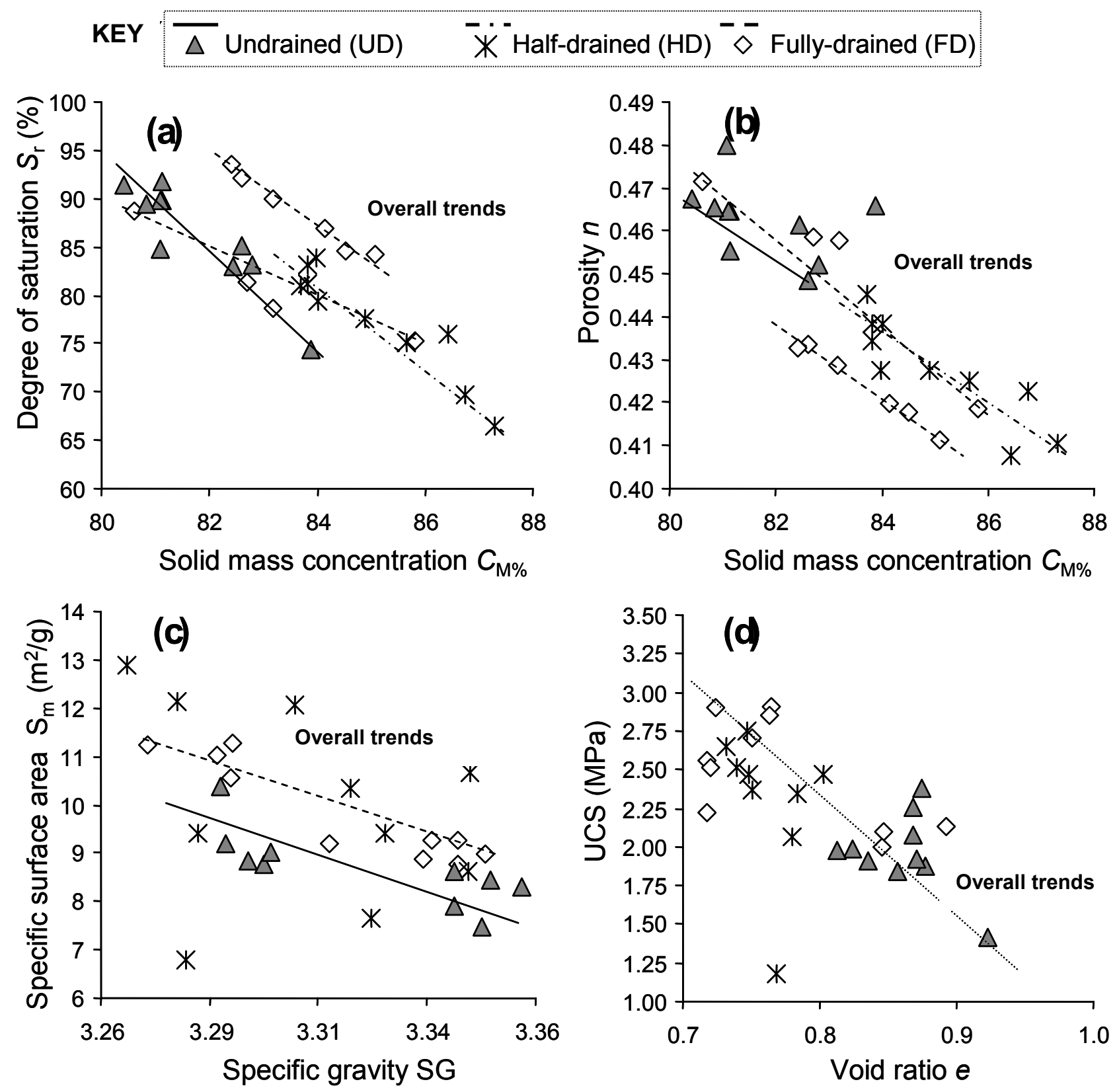

\section{Figure 6 Overall trends of column PB samples UCS and selected physical parameters}

Relationship between $S_{\mathrm{r}}$ and $\boldsymbol{C}_{\mathrm{M} \%}$ : the overall trend on Figure 6a indicates that a moderated increase in the paste fill solid mass concentration (of about $4 \%$ for HD and UD columns and 3\% for the FD column) involves a drastic decrease in its degree of saturation (of about 19\% for HD and UD columns and 10\% for the FD column) according to the column drainage configuration. There is also a good correlation between $\mathrm{S}_{\mathrm{r}}$ and $C_{\mathrm{M} \%}$ for HD and UD paste fill sample data over the entire height of the columns. For the FD paste fill sample data this good correlation exists only for each of the two layers.

Relationship between $\mathbf{n}$ and $\boldsymbol{C}_{\mathbf{M} \%}$ : Figure $6 \mathrm{~b}$ shows the relationship between the paste fill long-term porosity $n$ and the corresponding solid mass concentration $C_{\mathrm{M} \%}$. This figure also shows that a little increase in the 
$C_{\mathrm{M} \%}$ value (of about 3.5\%) leads to a very little decrease of the porosity (of about 0.03 ) regardless of the column drainage configuration.

Relationship between $\boldsymbol{S}_{\mathrm{m}}$ and SG: the overall trends on Figure 6c exhibit a significant correlation between the specific surface area $S_{\mathrm{m}}$ and the specific gravity SG for FD and UD paste fill sample data. But this correlation does not exist for the HD paste fill sample data which are very scattered. Figure 6c also shows that a marginal decrease in the paste fill specific gravity SG (of about 0.1 ) involves a significant increase in its specific surface area $\mathrm{S}_{\mathrm{m}}$ (of about $2.5 \mathrm{~m}^{2} / \mathrm{g}$ ).

Relationship between UCS and e: Figure 6d shows that there is no significant correlation between the UCS value (varying between 1.38 and $2.94 \mathrm{MPa}$ ) and the final void ratio of paste fill regardless of the column drainage configuration. But the overall trend of all the three column data seems to indicate that a big decrease in the void ratio (of about 0.2 ) leads to a big increase in the UCS value (of about $1.75 \mathrm{MPa}$ ).

\section{CONCLUSIONS}

This paper presents the results of a prospective experimental study of self-weight consolidation behaviour of paste backfill poured into settling columns of $3 \mathrm{~m}$ high. The results showed that the total percentage of drained water and the maximum observed self-weight consolidation settlement occur mainly within the first 72 hours since the columns are filled. The maximum drainage percentage of $15 \%$ and $8 \%$ of the PB total water was observed for the fully-drained (FD) and the half-drained (HD) columns. The maximum measured PB settlement was of $16.4 \mathrm{~cm}, 8.5 \mathrm{~cm}$ and $7.5 \mathrm{~cm}$ for the FD, HD and UD (undrained) columns respectively. The corresponding volumetric strains were $5.5 \%, 2.8 \%$ and $2.5 \%$ respectively. The field observed strain of PB at Louvicourt mine varies between 3.3\%-5\% and suggesting that in situ backfilled stopes behave in a similar way to the fully-drained (FD) or the half-drained (HD) conditions. The compression tests results showed that the highest compressive strength of PB was obtained from the FD (UCS $>2.9$ MPa) and HD $(\mathrm{UCS}>2.7 \mathrm{MPa}$ ) columns $\mathrm{PB}$ samples. In terms of physical properties, a good relationship was found between the degree of saturation $\mathrm{S}_{\mathrm{r}}$ /porosity $n$ and solid mass concentration $C_{\mathrm{M} \%}$. For the FD and UD backfill samples, a good relationship exists between $\mathrm{S}_{\mathrm{m}}$ and $\mathrm{SG}$. The results also show that the void ratio $e$ (or porosity $n$ ) exhibits a direct dependency on the corresponding UCS value. Further in situ investigations using adequately instrumented columns are needed to better understand the effect of self-weight consolidation of paste backfill on its short- and long-terms mechanical, physical and geochemical behaviours.

\section{ACKNOWLEDGEMENTS}

This research project was financially supported by the FUQAT, parts of IRSST, NSERC and NATEQ funds. The authors gratefully acknowledge their support. We would like to acknowledge Nil Gaudet, Hugues Bordeleau and Franck Gagnon from URSTM Laboratory for the invaluable technical assistance. We would 
also like to thank Bernard Dallaire, Jean Cayouette and Mathieu Belisle from Louvicourt Mine for their logistical support throughout this project.

\section{REFERENCES}

Been, K. and Sills, G.C. (1981) Self-weight consolidation of soft soils: an experimental and theoretical study, Géotechnique, 31, 4, pp. 519-535.

Belem, T., Benzaazoua, M., Bussière, B. and Dagenais, A.-M. (2002) Effects of settlement and drainage on strength development within mine paste backfill, in Proceedings of Tailings and Mine Waste'02, 27-30 January 2002, Fort Collins, Colorado, Balkema, Rotterdam, pp. 139-48.

Belem, T., Benzaazoua, M. and Bussière, B. (2000) Mechanical behaviour of cemented paste backfill, in Proceedings of 53th Canadian Geotechnical Conference: "Geotechnical Engineering at the dawn of the third millennium", 15-18 October 2000, Montréal, Vol. 1, pp. 373-380.

Belem, T., Bussière, B. and Benzaazoua, M. (2001) The effect of microstructural evolution on the physical properties of paste backfill, in Proceedings of Tailings and Mine Waste'01, January 16-19, Fort Collins, Colorado, A.A. Balkema, Rotterdam, pp. $365-374$.

Belem, T., Harvey, A., Simon, R. and Aubertin, M. (2004) Measurement and prediction of internal stresses in an underground opening during its filling with cemented fill, in Proceedings of the 5th Int. Symp. on Ground Support in Mining and Underground Construction. Villaescusa \& Potvin (eds.), 28-30 September 2004, Perth, Western Australia, Australia, Tayler \& Francis Group, London, pp. $619-630$.

Benzaazoua, M., Belem, T. and Jolette, D. (2000) Chemical stability investigation and its impact on the quality of cemented backfill (in French), IRSST Report No. R-260, 172p.

Benzaazoua, M., Fall, M. and Belem, T. (2004) A contribution to understanding the hardening process of cemented pastefill, Minerals Engineering. 17, 2, pp. 141-152.

Cayouette, J. (2003) Optimization of the paste backfill plant at Louvicourt mine, CIM Bulletin, 96, 1075, pp. 51-57.

le Roux, K.A., Bawden, W.F. and Grabinsky, M.W.F. (2002) Assessing the interaction between hydration rate and fill rate for a cemented paste backfill, In Proceedings on the 55th Canadian Geotechnical and 3rd joint IAH-CNC Groundwater specialty Conferences, Niagara Falls, Ontario, October, 20-23, 2002, pp. 427-432.

Revell M.B. (2004) Paste - How strong is it? In Proceedings of the 8th International Symposium on Mining with Backfill, Septembre 2004, Beijing, The Nonferrous Metals Society of China, pp. 286-294.

Wickland, B.E. and Wilson, G.W. (2005) Self-weight consolidation of mixtures of mine waste rock and tailings, Can. Geotech. J. 42 , pp. 327-339. 